\title{
Evaluating the effect of a water exercise routine on the postural stability of the elderly
}

\section{Evaluación del efecto de una rutina de ejercicios acuáticos sobre la estabilidad postural de adultos mayores}

\author{
Natali Olaya Mira1 ${ }^{1}$ Isabel Cristina Soto Cardona ${ }^{2}$ Laura Vanesa Martínez Osorno ${ }^{3}$ \\ Darwin Raúl Mercado Díaz ${ }^{3}$ Luisa María Henao Ceballos ${ }^{3}$ (D) \\ nataliolaya@itm.edu.co \\ 1 Instituto Tecnológico Metropolitano, Facultad de Ciencias Exactas y Aplicadas, Biomedical Research \\ and Innovation Group - GI2B. Medellín, Colombia., 2 Instituto Tecnológico Metropolitano, Facultad de \\ Ciencias Exactas y Aplicadas, Biomechanical and Rehabilitation Laboratory. Medellín, Colombia., 3 \\ Instituto Tecnológico Metropolitano, Facultad de Ciencias Exactas y Aplicadas, Biomedical Engineering \\ Program. Medellín, Colombia.,
}

Citation: .Olaya MN, Soto CIC, Mar'tinez OLV, Mercado DRD, Henao CLM. Evaluating the effect of a water exercise routine on the postural stability of the elderly Colomb Méd (Cali), 2021;

52(3):e2004537 http://doi. org/10.25100/cm.v52i 3.4537

Received : 07 Sep 2020

Revised: $\quad 30$ Jan 2021

Accepted : 24 Apr 2021

Published: 11 Jun 2021

Keywords:

postural balance, stabilometry, electromyography, hydrotherapy

Palabras clave:

Balance postural, estabilometría, electromiografía, hidroterapia

Copyright: @ 2021 Universidad del Valle

(c) (6) $\odot$

\section{Abstract}

\section{Background:}

Postural stability enables humans to maintain the center of mass of their body within their base of support. Nevertheless, over time, such stability is affected by different factors such as age, repetitive strain, and accidents. Although studies in this field have investigated the effectiveness of hydrotherapy, only a few of them have explored its influence on postural stability, which is reflected in a lack of research that estimates its impact on rehabilitation.

\section{Aim:}

To determine the immediate and final effects of an aquatic routine protocol on the postural stability of elderly subjects.

\section{Methods:}

The postural stability of 20 adults over 60 years of age was analyzed using electromyographic and baropodometric methods. Electromyographic signals were obtained from the tibialis anterior, soleus, both gastrocnemius, vastus medialis, and biceps femoris to calculate the coactivation percentage of the muscles in charge of postural stability. The baropodometric data were collected to analyze the area of the stabilometric ellipse, mean plantar pressure, and weight distribution percentage.

\section{Results:}

The outcome of both methods revealed improvements in the elderly patients after the aquatic routine protocol was applied, which indicates that the type of water exercises implemented in this study has positive effects on their postural stability.

\section{Conclusions:}

The postural stability of the elderly participants was improved after each session because their stability index decreased along with the electrical activity of some muscle pairs, their body weight was better distributed, and the area of body oscillation was reduced. However, this effect was immediate and not final. 


\section{Conflicts of interest:}

None declared

\section{Acknowledgments:}

The authors would like to thank the Laboratorio de Biomecánica e Ingeniería de Rehabilitación at the Instituto Tecnológico Metropolitano for providing the infrastructure and the assistant staff necessary to conduct this study

\section{Corresponding author:}

Natali Olaya Mira. Facultad de Ciencias Exactas y Aplicadas Instituto Tecnológico Metropolitano. Telephone: +574 4405100 ext. 5266. Email: nataliolaya@itm.edu.co

\section{Resumen}

\section{Antecedentes:}

La estabilidad postural permite a los humanos mantener el centro de masa de su cuerpo dentro de su base de apoyo. Sin embargo, con el tiempo, dicha estabilidad se ve afectada por diferentes factores como la edad, el esfuerzo repetitivo y los accidentes. Si bien los estudios en este campo han investigado la efectividad de la hidroterapia, solo algunos de ellos han explorado su influencia en la estabilidad postural, lo que se refleja en la falta de investigaciones que estimen su impacto en la rehabilitación.

\section{Objetivo:}

Determinar los efectos inmediatos y finales de un protocolo de rutina acuática sobre la estabilidad postural de adultos mayores.

\section{Métodos:}

Se analizó la estabilidad postural de 20 adultos mayores de 60 años mediante métodos electromiográficos y baropodométricos. Se obtuvieron señales electromiográficas del tibial anterior, sóleo, gastrocnemio, vasto interno y bíceps femoral para calcular el porcentaje de coactivación de los músculos encargados de la estabilidad postural. Los datos baropodométricos se recolectaron para analizar el área de la elipse estabilométrica, la presión plantar media y el porcentaje de distribución del peso corporal.

\section{Resultados:}

Ambos métodos mostraron mejoras en los pacientes luego de la aplicación del protocolo de rutina acuática, lo que indica que el tipo de ejercicios acuáticos implementados en este estudio tiene efectos positivos en su estabilidad postural.

\section{Conclusiones:}

La estabilidad postural de los participantes mejoró después de cada sesión porque su índice de estabilidad disminuyó junto con la actividad eléctrica de algunos pares de músculos, su peso corporal se distribuyó mejor y se redujo el área de oscilación corporal. Sin embargo, este efecto fue inmediato y no definitivo.

\section{Remark}

\section{1) Why was this study conducted?}

This study was carried out to test the effect of an aquatic exercise routine on the stability of the elderly by two different methods: stabilometry and electromyography.

\section{2) What were the most relevant results of the study?}

Both methods revealed immediate improvements in the postural stability of the elderly after the application of the routine aquatic protocol.

\section{3) What do these results contribute?}

In the decision-making of physiatrists, physiotherapists and other related health personnel when prescribing therapies in the elderly population. They can give priority to those activities that involve aquatic exercises when it is necessary to improve the postural stability of this population in the rehabilitation processes. 


\section{Introduction}

As a result of better treatments to cure diseases and multiple other reasons, most people's life expectancy has been extended to 60 years or more. The number of seniors will almost double in the coming years ${ }^{1}$, and they will suffer from conditions such as balance disorders, which lead to musculoskeletal disorders (MSDs) and are generally degenerative. This situation poses serious problems for public health and the overall quality of life $\mathrm{e}^{2,3}$ because such medical conditions significantly increase the cost of rehabilitation processes if they are not timely prevented or treated ${ }^{4}$.

Water exercises have proven to be effective and efficient to restore body functions in the short term ${ }^{5,6}$ because the movements are slower and more predictable than on the ground, providing more significant sensory-motor feedback, balance, stability, and coordination, and facilitating postures such as a standing position ${ }^{7}$. Nevertheless, few studies so far have examined the influence of water on postural stability, and most of them are anecdotal or biased due to a lack of standardized protocols to evaluate its impact on rehabilitation ${ }^{8}$.

This study evaluates the postural stability of elderly individuals based on their muscle coactivation and baropodometric variables to assess the immediate and final effects of implementing a water exercise protocol.

In this study, two techniques were employed to assess postural stability. First, muscle coactivation (i.e., the simultaneous contraction of agonist and antagonist muscles) was measured using electromyography ${ }^{9}$, and its role in maintaining articular stability was demonstrated ${ }^{10}$. Second, a baropodometric platform was used to measure the area of stabilometric ellipse, mean plantar pressure, and weight distribution percentage on the footprint ${ }^{11}$; therefore, it was proven that the second technique can be used for quantifying postural control ${ }^{12,13}$.

\section{Materials and Methods}

\section{Type of study}

This was a prospective cohort pilot study conducted with a single group of elderly individuals. Participants were recruited from INDER Medellín, an active senior group. The protocol was followed in 12 one-hour sessions over four weeks, and it was finished when the subject abandoned or finished the study.

\section{Population}

None of the participants had been diagnosed with joint disorders in lower limbs such as arthrosis or arthritis, disc wounds with radiating pain to lower limbs from L3-S1, neuropathies, neurological disorders (ataxia or multiple sclerosis), cerebellar problems, epilepsy, vertigo, diabetes, peripheral venous insufficiency, severe kidney disease, urinary and/or anal incontinence, open wounds, or amputation of lower limbs. The subjects had to attend the twelve sessions to be included in this study even after being selected. Before their voluntary participation, they signed an informed consent approved by the Ethics Committee of Instituto Tecnológico Metropolitano, which observes the principles established in the Declaration of Helsinki (DoH), as recommended by the World Medical Association ${ }^{14}$.

\section{Exercise protocol}

This exercise protocol was followed in a 1.63-meter-deep sports pool at Instituto Tecnológico Metropolitano. The water exercise routine for lower limbs was focused on postural stability and divided into 12 one-hour sessions over four weeks. In each of the four weeks, participants performed different exercises (at least fifteen repetitions after the respective warm-up exercises), as follows: 

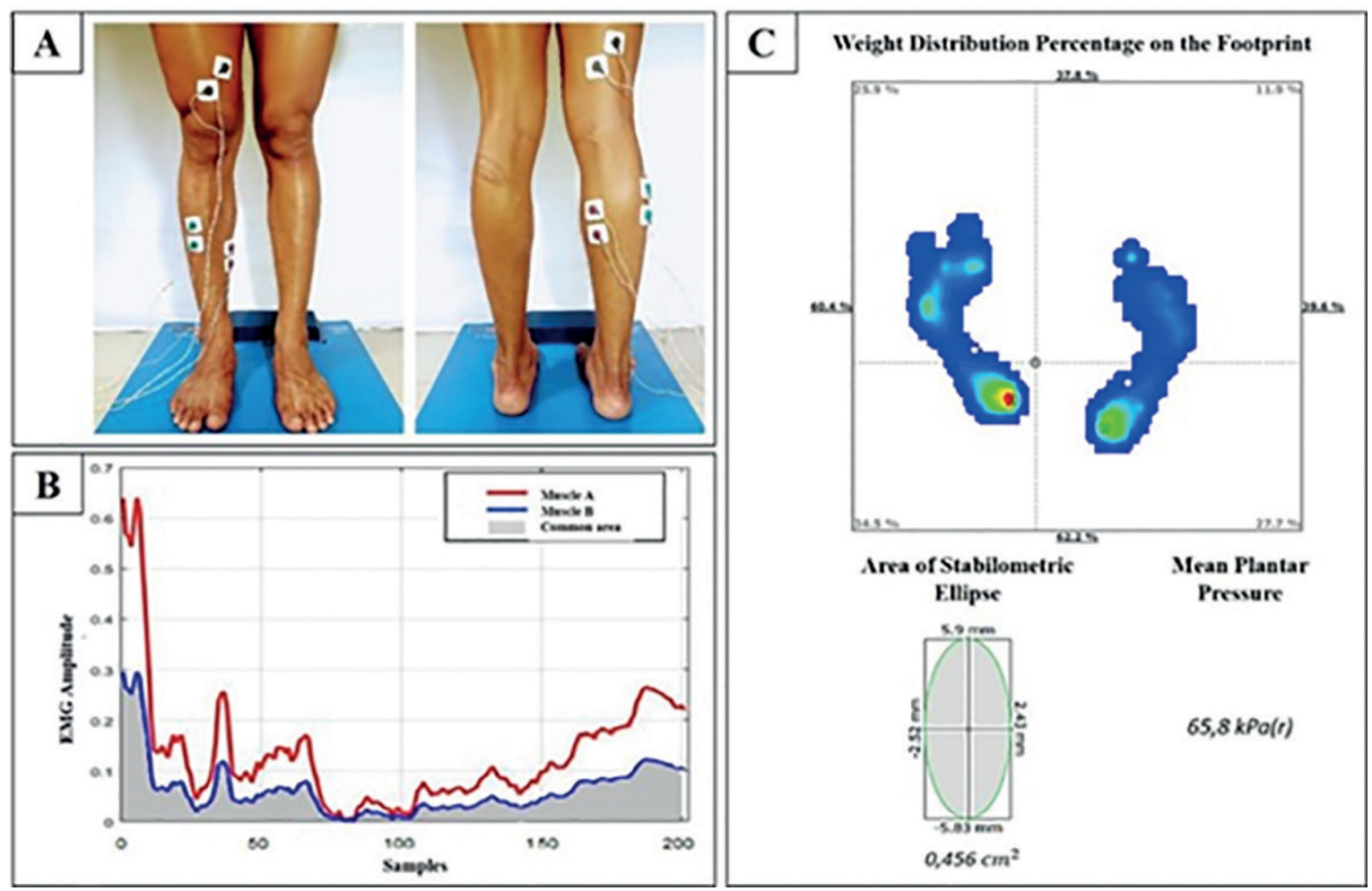

Figure 1. (A) Placement of the electrodes: front (TA, S, and FB muscles) and back (GM, GL, and VM muscles). (B) Area of the muscle coactivation percentage. (C) Baropodometric variables (weight distribution, area of the stabilometric ellipse, and mean plantar pressure).

(i) stretching to work on their joint mobility and flexibility; (ii) eccentric joint movements with bipedal standing to improve strength and proprioception; (iii) seated marching workout and stairs with unipedal standing to work on balance and proprioception; and (iv) exercises to identify the joint position (eyes open/closed) with unipedal and bipedal standing for coordination, speed, and functionality.

\section{Signal acquisition}

Surface electromyography was used to capture muscle coactivation signals, and a baropodometric platform recorded their plantar pressures. The signals were obtained while the participants were standing on both feet on the platform for 6 seconds before and after the water exercise protocol to calculate all the measurements and obtain 24 signals per subject.

\section{Stability measured by muscle coactivation}

The muscle coactivation percentage of the subjects' self-reported dominant leg was calculated by means of surface electromyography (EMG) of the six muscle groups that are directly involved in the stability of lower limbs: tibialis anterior (TA), soleus (S), gastrocnemius medialis (GM), gastrocnemius lateralis (GL), vastus medialis (VM), and biceps femoris (FB) ${ }^{15}$ (Figure 1A).

The protocol of the SENIAM (Surface Electromyography for the Non-Invasive Assessment of Muscles) project was applied to place the electrodes ${ }^{16}$. The signals were acquired with an ML138 differential amplifier connected to a PowerLab 16/35 polygraph manufactured by AD Instruments Inc. A $2-\mathrm{kHz}$ sampling frequency was used, and the signal was preprocessed with LabChart Pro software implementing a $60-\mathrm{Hz}$ notch filter and another passband with a cutoff frequency between 10 and $500 \mathrm{~Hz}$.

Matlab was employed to calculate the coactivation percentage. The signals obtained from the muscles were filtered once again using a fifth-order digital Butterworth bandpass filter with 
cutoff frequencies between 10 and $300 \mathrm{~Hz}$. The root mean square (RMS) of each resulting signal was calculated with a window of 250 samples and an overlapping of 50 samples. Finally, four muscle groups (VM/BF, T/S, T/GM, and T/GL) were created to be normalized using the following equation:

$$
X_{n}=\frac{X-X_{\min }}{X_{\max }-X_{\min }}
$$

Where $X_{n}$ denotes the normalized signal; $X$, the original signal; and $X_{\min }$ and $X_{\max }$, the minimum and maximum values of the original signal, respectively. Afterward, the coactivation percentage between muscles was calculated using Equation $2{ }^{17}$.

$$
\% C O A C T=2 \times \frac{A \& B \text { common area }}{\text { B area }+ \text { A area }} \times 100
$$

where \% COACT is the coactivation percentage between the agonist and antagonist muscles; A area, the area under the curve of the processed EMG signal of the A muscle; $B$ area, the area under the curve of the processed EMG signal of the B muscle; and A \& B common area, the region of activity shared by the $\mathrm{A}$ and $\mathrm{B}$ muscles (Figure $1 \mathrm{~B}$ ) ${ }^{17}$. Note that, when this percentage approaches $100 \%$, stability is low; and, when it tends to $0 \%$, stability is high ${ }^{18,19}$.

\section{Stability measured by baropodometry}

The pressure platform Ecowalk and its software EcoFoot 4.0 calculated the baropodometric variables in this study. Such measurement system comprises a $67-\mathrm{cm}$-long, 54-cm-wide portable platform equipped with 2,300 capacitive sensors. After the participants stood on the platform and maintained their standard anatomical position for 6 seconds, the following data were collected: area of stabilometric ellipse, mean plantar pressure, and weight distribution percentage (Figure 1C). Said distribution was calculated as the difference between the anterior and posterior distribution of weight; likewise, the lateral distribution resulted from subtracting $50 \%$ from the lateral distribution of the dominant foot because only one foot was measured. The variables mentioned above describe the stability of each participant ${ }^{11,20}$.

\section{Characterization of the captured data}

The immediate and long-term effects of this exercise protocol were analyzed. The former were studied by comparing each variable before and after the exercise sessions; and the latter were established by comparing the measurements before the first routine and after the twelfth session. Additionally, the sessions that had a significant influence on the measured variables were examined in detail.

The data were statistically analyzed using SPSS software (version 24). The Kolmogorov- Smirnov test for normality was employed with a significance level of 0.05 . Some of the data presented normality, however, a non-parametric test, Wilcoxon signed rank test were applied to all the variables to determine significant differences between the groups of variables mentioned above for each exercise protocol effect.

\section{Results}

Snowball sampling, a non-probability technique, was implemented to select, among 42 adults, only 20 participants. As a result, the sample was composed of 17 women and 3 men aged $62.5 \pm$ 9.2. Their data were collected between August and December 2018 to measure the effectiveness of the aquatic exercise protocol in improving postural stability. Six participants abandoned the study after the ninth session for personal reasons or due to incompatibilities 
Table 1. Immediate effect of the exercise protocol.

\begin{tabular}{|c|c|c|c|c|c|c|c|}
\hline \multirow[t]{2}{*}{ Variables } & \multicolumn{2}{|l|}{ Measurement } & \multirow[t]{2}{*}{ Mean \pm SD } & \multirow[t]{2}{*}{ Median } & \multirow{2}{*}{$\begin{array}{c}\text { Kolmogorov- } \\
\text { Smirnov Test } \\
\text { P-value }\end{array}$} & \multicolumn{2}{|c|}{ Wilcoxon signed rank test } \\
\hline & & & & & & $\begin{array}{c}\text { Significance } \\
\text { Level }\end{array}$ & $\begin{array}{l}\text { Significant } \\
\text { difference }\end{array}$ \\
\hline \multirow[t]{8}{*}{ Muscle Coactivation } & \multirow{2}{*}{$\begin{array}{l}\text { Vastus Medialis vs Biceps } \\
\text { Femoris (\%) }\end{array}$} & Before & $42.28 \pm 23.12$ & 42.95 & 0.004 & \multirow[t]{2}{*}{614.0} & \multirow[t]{2}{*}{ No } \\
\hline & & After & $42.68 \pm 21.43$ & 43.57 & 0.200 & & \\
\hline & \multirow[t]{2}{*}{$\begin{array}{l}\text { Tibialis anterior vs } \\
\text { Soleus }(\%)\end{array}$} & Before & $43.25 \pm 22.78$ & 42.28 & 0.005 & \multirow[t]{2}{*}{510.0} & \multirow[t]{2}{*}{ No } \\
\hline & & After & $41.29 \pm 24.46$ & 42.95 & 0.002 & & \\
\hline & \multirow[t]{2}{*}{$\begin{array}{l}\text { Tibialis anterior vs } \\
\text { Gastrocnemius Medialis (\%) }\end{array}$} & Before & $44.07 \pm 22.62$ & 43.65 & 0.002 & \multirow[t]{2}{*}{33.0} & \multirow[t]{2}{*}{ Yes } \\
\hline & & After & $39.29 \pm 22.13$ & 40.64 & 0.007 & & \\
\hline & \multirow{2}{*}{$\begin{array}{l}\text { Tibialis anterior vs Gastroc- } \\
\text { nemius Lateralis (\%) }\end{array}$} & Before & $44.19 \pm 24.45$ & 47.35 & 0.000 & \multirow[t]{2}{*}{224.0} & \multirow[t]{2}{*}{ No } \\
\hline & & After & $41.39 \pm 24.89$ & 41.30 & 0.003 & & \\
\hline \multirow[t]{8}{*}{ Stabilometry } & \multirow[t]{2}{*}{$\begin{array}{l}\text { Anteroposterior weight } \\
\text { distribution (\%) }\end{array}$} & Before & $27.15 \pm 17.18$ & 24.20 & 0.007 & \multirow[t]{2}{*}{128.0} & \multirow[t]{2}{*}{ No } \\
\hline & & After & $29.16 \pm 17.31$ & 27.60 & 0.044 & & \\
\hline & \multirow{2}{*}{$\begin{array}{l}\text { Lateral weight } \\
\text { distribution (\%) }\end{array}$} & Before & $20.37 \pm 13.83$ & 18.10 & 0.001 & \multirow[t]{2}{*}{218.0} & \multirow[t]{2}{*}{ No } \\
\hline & & After & $22.06 \pm 15.23$ & 19.90 & 0.000 & & \\
\hline & \multirow[t]{2}{*}{ Area of ellipse (cm2) } & Before & $14.16 \pm 27.40$ & 3.99 & 0.000 & \multirow[t]{2}{*}{21.0} & \multirow[t]{2}{*}{ Yes } \\
\hline & & After & $16.52 \pm 22.79$ & 8.40 & 0.000 & & \\
\hline & \multirow[t]{2}{*}{ Mean pressure $(\mathrm{kPa})$} & Before & $22.71 \pm 12,07$ & 19.25 & 0.000 & \multirow[t]{2}{*}{12.0} & \multirow[t]{2}{*}{ Yes } \\
\hline & & After & $21.26 \pm 11.74$ & 19.00 & 0.000 & & \\
\hline
\end{tabular}

in their schedules. No accidents were reported during the implementation of the protocol. The immediate effects of the exercise protocol were analyzed by comparing each one of the measurements before and after every exercise session. In the final effect, the first session before performing the protocol was compared with the twelfth session after performing the exercises.

\section{Immediate effect}

Regarding stability by coactivation, only the values of T/GM exhibited a significant difference. The coactivation of the tibialis anterior decreased compared to that of the gastrocnemii (T/GM and T/GL), while the coactivation of VM/BF and T/S increased slightly; hence, only two of the four muscle pairs presented reduced coactivation (Table 1).

When postural stability was determined by means of baropodometry, only the ellipse area and mean pressure exhibited significant differences, the latter being the only one that did not show an increase after the protocol was applied (Table 1). Additionally, more body weight was distributed on the right foot in $54 \%$ of the population, and on the hindfoot in $86 \%$ of them.

\section{Final effect}

The stability by coactivation of the $\mathrm{VM} / \mathrm{BF}$ muscle pair was the only variable that decreased in the long term, although it showed no significant difference after the entire exercise protocol (Table 2).

As in the case of the immediate effect measured by baropodometry, the area of the ellipse presented a significant difference. Nevertheless, the mean pressure did not, which was reflected in a decrease in all the variables, except for the area of the stabilometric ellipse (Table 2). Additionally, more body weight was distributed on the right foot in $57 \%$ of the population, and on the hindfoot in $79 \%$ of them. 
Table 2. Final effect of the exercise protocol.

\begin{tabular}{|c|c|c|c|c|c|c|c|}
\hline \multirow[t]{2}{*}{ Variables } & \multicolumn{2}{|l|}{ Measurement } & \multirow[t]{2}{*}{ Mean \pm SD } & \multirow[t]{2}{*}{ Median } & \multirow{2}{*}{$\begin{array}{c}\text { Kolmogorov- } \\
\text { Smirnov Test } \\
\text { P-value }\end{array}$} & \multicolumn{2}{|c|}{ Wilcoxon signed rank test } \\
\hline & & & & & & $\underset{\text { Level }}{\substack{\text { Significance } \\
\text { Level }}}$ & $\begin{array}{l}\text { Significant } \\
\text { difference }\end{array}$ \\
\hline \multirow[t]{8}{*}{ Muscle Coactivation } & \multirow{2}{*}{$\begin{array}{l}\text { Vastus Medialis vs Biceps } \\
\text { Femoris (\%) }\end{array}$} & Before & $43.84 \pm 22.99$ & 42.96 & 0.200 & \multirow[t]{2}{*}{925.0} & \multirow[t]{2}{*}{ No } \\
\hline & & After & $40.89 \pm 20.05$ & 34.13 & 0.123 & & \\
\hline & \multirow[t]{2}{*}{$\begin{array}{l}\text { Tibialis anterior vs } \\
\text { Soleus (\%) }\end{array}$} & Before & $44.89 \pm 21.12$ & 37.13 & 0.042 & \multirow[t]{2}{*}{221.0} & \multirow[t]{2}{*}{ No } \\
\hline & & After & $35.14 \pm 24.44$ & 40.40 & 0.200 & & \\
\hline & \multirow[t]{2}{*}{$\begin{array}{l}\text { Tibialis anterior vs } \\
\text { Gastrocnemius Medialis (\%) }\end{array}$} & Before & $33.55 \pm 19.34$ & 30.71 & 0.156 & \multirow[t]{2}{*}{433.0} & \multirow[t]{2}{*}{ No } \\
\hline & & After & $42.28 \pm 22.39$ & 36.11 & 0.052 & & \\
\hline & \multirow{2}{*}{$\begin{array}{l}\text { Tibialis anterior vs Gas- } \\
\text { trocnemius Lateralis (\%) }\end{array}$} & Before & $41.79 \pm 29.03$ & 41.71 & 0.015 & \multirow[t]{2}{*}{975.0} & \multirow[t]{2}{*}{ No } \\
\hline & & After & $39.92 \pm 25.36$ & 41.10 & 0.200 & & \\
\hline \multirow[t]{8}{*}{ Stabilometry } & \multirow[t]{2}{*}{$\begin{array}{l}\text { Anteroposterior weight } \\
\text { distribution (\%) }\end{array}$} & Before & $33.13 \pm 20.24$ & 24.3 & 0.030 & \multirow[t]{2}{*}{221.0} & \multirow[t]{2}{*}{ No } \\
\hline & & After & $25.94 \pm 15.28$ & 23.9 & 0.200 & & \\
\hline & \multirow{2}{*}{$\begin{array}{l}\text { Lateral weight } \\
\text { distribution (\%) }\end{array}$} & Before & $27.53 \pm 17.31$ & 19.7 & 0.034 & \multirow[t]{2}{*}{158.0} & \multirow[t]{2}{*}{ No } \\
\hline & & After & $19.60 \pm 16.07$ & 14.40 & 0.145 & & \\
\hline & \multirow[t]{2}{*}{ Area of ellipse $\left(\mathrm{cm}^{2}\right)$} & Before & $3.60 \pm 6.70$ & 1.02 & 0.001 & \multirow[t]{2}{*}{8.0} & \multirow[t]{2}{*}{ Yes } \\
\hline & & After & $19.18 \pm 22.68$ & 8.93 & 0.054 & & \\
\hline & \multirow[t]{2}{*}{ Mean pressure $(\mathrm{kPa})$} & Before & $28.64 \pm 7.37$ & 19.85 & 0.200 & \multirow[t]{2}{*}{221.0} & \multirow[t]{2}{*}{ No } \\
\hline & & After & $16.34 \pm 9.47$ & 12.90 & 0.138 & & \\
\hline
\end{tabular}

\section{Discussion}

The slightly lower coactivation of most of the calf muscles that was found in this study may indicate an immediate improvement of the postural stability of the elderly after the water exercise protocol was applied. Such muscles are directly involved in the stability of lower limbs because they are located close to the ankle joint ${ }^{21}$, closer than the VM/BF muscle pair in the thigh, which has no direct influence on the postural stability of lower limbs. Additionally, studies suggest that the coactivation of the T/S muscles decreases mainly after an exercise routine on the floor ${ }^{22}$; therefore, water may produce changes in the activation of said group.

Nevertheless, there is no consensus in the field to compare the results of aquatic exercises with those of traditional balance therapy. Some evidence in related works shows there is no statistically significant difference between conventional therapy and hydrotherapy; therefore, regardless of the environment where therapy is performed, an improvement in postural stability can be achieved ${ }^{23}$. Even using other measuring instruments (e.g., Berg Balance scale and the Timed Up and Go test), perceived stability has been reported to be lower when the task is performed in the water compared to on the ground ${ }^{24,25}$.

The results of this study show an immediate increase in lateral and anteroposterior weight distribution, but a slight decrease in mean plantar pressure. This outcome may have expanded the area of the stabilometric ellipse, which is the variable most closely related to postural stability ${ }^{26}$.

The final coactivation of the VM/BF muscle pair was reduced, which suggests a general improvement in postural stability. This decrease in coactivation only in the thigh muscles and not the calf could indicate that the final proprioception exercises in the protocol focus more on that area.

It has been shown that stabilometric parameters measured using pressure platforms provide valid information about postural stability ${ }^{27}$. All the baropodometric variables in this study exhibited lower values in the long term, except for the stabilometric ellipse area, which is possibly 
due to the fact that a standard position was not established for participants to place their feet on the pressure platform and their base of support could affect said variable ${ }^{28}$.

This study has two limitations: (a) the pool water temperature and the feet posture on the pressure platform were not standardized and (b) there was no control group. As a result, future work should consider factors such as water temperature (typical hydrotherapy pools are between $33.5^{\circ}$ and $35.5^{\circ} \mathrm{C}$ ) because this aspect determines the behavior of seniors' bodies, as the heat transfer starts immediately after the initial immersion, affecting muscular behavior ${ }^{29}$. Furthermore, the support base should be measured or normalized as an additional variable related to stability ${ }^{30}$.

\section{Conclusion}

After the 12-session protocol was completed, the baropodometry and muscle coactivation showed improvements, which indicates that the water exercises considered in this work may have positive effects on postural stability. This protocol can be part of an optimal intervention strategy to prevent falls because it involves training to improve the strength and balance of patients with osteoarthritis, as claimed by Martínez-Amat et al. ${ }^{31}$.

\section{References}

1. Organización Mundial de la Salud. Informe mundial sobre el envejecimiento y la salud. Estados Unidos de América; 2015.

2. Negrín VR, Olavarría MF. Artrosis y ejercicio físico. Rev Médica Clínica Las Condes. 2014;25(5):805-11. doi: 10.1016/S0716-8640(14)70111-7

3. Storheim K, Zwart J. Musculoskeletal disorders and the global burden of disease study. Ann Rheum Dis. 2014;73(6):949-50. doi: 10.1136/annrheumdis-2014-205327

4. Giménez BS, Pulido MFJ, Trigueros CJ. Atención Primaria de Calidad. Guía de buena práctica clínica en artrosis. Madrid: International Marketing \& Communications, S.A. 2008.

5. Waller B, Munukka M, Multanen J, Rantalainen T, Poyhonen T, Nieminen MT, et al. Effects of a progressive aquatic resistance exercise program on the biochemical composition and morphology of cartilage in women with mild knee osteoarthritis: protocol for a randomised controlled trial. BMC Musculoskelet Disord. 2013;14:82. doi: 10.1186/1471-2474-14-82

6. Schencking M, Otto A, Deutsch T, Sandholzer H. A comparison of Kneipp hydrotherapy with conventional physiotherapy in the treatment of osteoarthritis of the hip or knee: protocol of a prospective randomised controlled clinical trial. BMC Musculoskelet Disord. 2009;10:104. doi: 10.1186/1471-2474-10-104

7. Pazos RJM, González RA. Técnicas de hioterapia: Hidrocinesiterapia. Fisioterapia. 2002;24: 34-42. doi: 10.1016/S0211-5638(01)73026-X

8. Severin AC, Burkett BJ, McKean MR, Sayers MGL. Biomechanical Aspects of Aquatic Therapy: A literature review on application and methodological challenges. J Fit Res. 2016; 5(1): 48-62.

9. Moore IS, Jones AM, Dixon SJ. Relationship between metabolic cost and muscular coactivation across running speeds. J Sci Med Sport. 2014;17:671-6. doi: 10.1016/j.jsams.2013.09.014

10. Rutkowska-kucharska A, Szpala A, Jaroszczuk S. Muscle coactivation during stability exercises in rhythmic gymnastics : A two-case study. Appl Bionics Biomech. 2018;2018:1-8. doi: 10.1155/2018/8260402 
11. Martínez-Nova A, Sánchez-Rodríguez R, Cuevas-García JC, Sánchez-Barrado E. Estudio baropodométrico de los valores de presión plantar en pies no patológicos. Rehabilitacion. 2007;41(4):155-60. doi: 10.1016/ s0048-7120(07)75509-3

12. Yildirim T, Ersoy Y. Distribution of plantar pressure in fibromyalgia patients. Med Sci. 2017;6(3):398-400. doi: 10.5455/medscience.2016.05.8576

13. Seketa G, Ortiz G, Wilches C, Perdomo O, Celic L, Lackovic I, et al. Simultaneous measurement of trunk orientation and centre of pressure for postural stability evaluation. In: Lackovic I, Vasic D, editors. 6th European Conference of the International Federation for Medical and Biological Engineering. Cham: Springer International Publishing; 2015. p. 363-6. doi: 10.1007/978-3-319-11128-5_91

14. Declaración de Helsinki. Investigación médica en seres humanos. The World Medical Association. 2013. Available from: https://www.wma.net/es/que-hacemos/etica-medica/declaracion-de-helsinki/

15. Hallal CZ, Marques NR, Vieira ER, Brunt D, Spinoso DH, Castro A, et al. Lower limb muscle coactivation levels in healthy younger and older adults during functional dual-task gait. Motriz Rev Educ Fis. 2013;19(3):6206. doi: $10.1590 / \mathrm{S} 1980-65742013000300013$

16. Merletti R, Rau G, Disselhorst-Klug C, Stegeman DF, Hagg GM. SENIAM project. Surface ElectroMyoGraphy for the Non-Invasive Assessment of Muscles. 2018. Available from: http://www.seniam.org/

17. Candotti CT, Loss JF, Bagatini D, Soares DP, da Rocha EK, de Oliveira AR, et al. Cocontraction and economy of triathletes and cyclists at different cadences during cycling motion. J Electromyogr Kinesiol. 2009;19(5):915-21. doi: 10.1016/j.jelekin.2008.04.008

18. Le P, Best TM, Khan SN, Mendel E, Marras WS. A review of methods to assess coactivation in the spine. J Electromyogr Kinesiol. 2017; 32:51-60. doi: 10.1016/j.jelekin.2016.12.004.

19. Le P, Aurand A, Dufour JS, Knapik GG, Best TM, Khan SN, et al. Development and testing of a moment-based coactivation index to assess complex dynamic tasks for the lumbar spine. Clin Biomech. 2017; 46: 23-32. doi: 10.1016/j.clinbiomech.2017.05.001

20. Popovich M, Pappas IP, Nakazawa K, Keller T, Morari M, et al. Stability criterion for controlling standing in able-bodied subjects. J Biomech. 2000;33:1359-68. doi: 10.1016/S0021-9290(00)00123-8

21. O'Sullivan SB, Schmitz TJ. Improving functional outcomes in physical rehabilitation. Pennsylvania, United States: F.A. Davis Company; 2016.

22. Nagai K, Yamada M, Tanaka B, Uemura K, Mori S, Aoyama T, et al. Effects of balance training on muscle coactivation during postural control in older adults: A randomized controlled trial. J Gerontol A Biol Sci Med Sci. 2012; 67(8):882-9. doi: 10.1093/gerona/glr252.

23. Cano BJ, Olaya MN, Soto CIC. Evaluacion estadística de la estabilidad postural en pacientes con artrosis de rodilla por medio de la coactivación muscular. Comunicaciones Estadística. 2019;12(1):53-69. doi: $10.15332 / 23393076 / 5291$

24. Louder T, Bressel E, Baldwin M, Dolny DG, Gordin R, Miller A. Effect of aquatic immersion on static balance. Int J Aquat Res Educ. 2014;8(1):53-65. doi: 10.1123/ijare.2013-0014

25. Montagna JC, Santos BC, Battistuzzo CR, Loureiro APC. Effects of aquatic physiotherapy on the improvement of balance and corporal symmetry in stroke. Int J Clin Exp Med. 2014;7(4):1182-7. 
26. Hue O, Simoneau M, Marcotte J, Berrigan F, Doré J, Marceau P, et al. Body weight is a strong predictor of postural stability. Gait Posture. 2007;26(1):32-8. doi: 10.1016/j.gaitpost.2006.07.005

27. Pizzigalli L, Filippini A, Ahmaidi S, Jullien $H$, Rainoldi A. Prevention of falling risk in elderly people: the relevance of muscular strength and symmetry of lower limbs in postural stability. J Strength Cond Res. 2011;25(2):567-74. doi: 10.1519/JSC.0b013e3181d32213

28. Zequera M, Perdomo O, Wilches C, Vizcaya P. Pilot study: Assessing repeatability of the EcoWalk platform resistive pressure sensors to measure plantar pressure during barefoot standing. J Phys Conf Ser. 2013;450(1) 012029. doi: 10.1088/1742-6596/450/1/012029

29. Ellapen TJ, Hammill H V., Swanepoel M, Strydom GL. The benefits of hydrotherapy to patients with spinal cord injuries. Afr J Disabil. 2018;7(0):450. doi: 10.4102/ajod.v7i0.450

30. McAndrew Young PM, Dingwell JB. Voluntary changes in step width and step length during human walking affect dynamic margins of stability. Gait Posture. 2012;36(2):219-24. doi: 10.1016/j.gaitpost.2012.02.020

31. Martínez-Amat A, Hita-Contreras F, Lomas-Vega R, Caballero-Martínez I, Alvarez PJ, Martínez-López E. Effects of 12-week propioception training program on postural stability, gait, and balance in older adults: a controlled clinical trial. J Strength Cond. 2013;27(8):2180-8. doi: 10.1519/JSC.0b013e31827da35f. 